\title{
The Devonian placoderm fish Bothriolepis canadensis revisited with three-dimensional digital imagery
}

\author{
Isabelle Béchard, Félix Arsenault, Richard Cloutier, and Johanne Kerr
}

\begin{abstract}
The external morphology of the Late Devonian placoderm fish Bothriolepis canadensis from the Escuminac Formation (Miguasha, Canada) is reanalyzed using cutting-edge technology in three-dimensional (3D) digital imagery such as 3D surface scanner and 3D modeling software. Nineteen well-preserved specimens of $B$. canadensis were used to reconstruct a 3D digital model of the dermal armor, whereas four specimens were used to reconstruct the fleshy posterior part of the body. Digital manipulation of the model allows us to investigate some biomechanical aspects and constraints of the morphology. Mobility of the cephalic armor, submarginal plates and pectoral fins has been previously hypothesized based on inaccurate reconstructions. In contrast to previous interpretations, there is no indication of mobility between the cephalic and thoracic armors. The submarginal plate is immobilized on the cephalic armor; a gill opening is located between the submarginal and anterior ventrolateral plates of the thoracic armor. The median dorsal ridge of the thoracic armor forms a hydrodynamic dorsal crest with its maximum height along the posterior median dorsal plate, which most likely has an important role in locomotion. The fully retracted and protracted $\left(70^{\circ}\right)$ position of the pectoral fins allows only for restricted movement excluding the possibility of stroking and using them as anchoring devises. Maximum of mobility is reached in a protracted angle of $16^{\circ}$, which allows a rotation of $32^{\circ}$ around the brachial process and $15^{\circ}$ in an up-and-down movement. The 3D model of $B$. canadensis brings out unexpected novelties on one of the supposedly best-known Devonian fish.
\end{abstract}

Isabelle Béchard. Université du Québec à Rimouski, 300 allée des Ursulines, Rimouski, Québec, G5L 3A1, Canada

Present address; Centre de développement et de recherche en imagerie numérique, 608 avenue SaintRédempteur, Matane, Québec, G4W 0E1, Canada. bechard.isabelle@cdrin.com

Félix Arsenault. Centre de développement et de recherche en imagerie numérique, 608 avenue Saint-

Rédempteur, Matane, Québec, G4W 0E1, Canada. arsenault.felix@cdrin.com

Richard Cloutier. Département de Biologie, Chimie et Géographie, Université du Québec à Rimouski, 300

allée des Ursulines, Rimouski, Québec, G5L 3A1, Canada. richard_cloutier@uqar.ca

Johanne Kerr. Parc national de Miguasha, 231 route Miguasha Ouest, Nouvelle, Québec, G0C 2E0,

Canada. kerr.johanne@sepaq.com

PE Article Number: 17.1.2A

Copyright: Society for Vertebrate Paleontology January 2014

Submission: 8 July 2013. Acceptance: 15 December 2013

Béchard, Isabelle, Arsenault, Félix, Cloutier, Richard, and Kerr, Johanne. 2014. The Devonian placoderm fish Bothriolepis canadensis revisited with three-dimensional digital imagery. Palaeontologia Electronica Vol. 17, Issue 1;2A; 19p;

palaeo-electronica.org/content/2014/647-3d-bothriolepis 
Keywords: Bothriolepis canadensis; Placodermi; reconstruction; three-dimensional (3D); 3D model; 3D scanner; locomotion; augmented reality

\section{Note from authors}

A mobile application is available to enhance Figures 2 and 7 of this article. PaleoAR is an augmented reality application available (free) at the AppStore. Figures should be printed and used as a target with the application.

\section{INTRODUCTION}

Among placoderms, including more than 60 species of Bothriolepis (Denison, 1978; Thomson and Thomas, 2001; Young, 2010), the Late Devonian antiarch Bothriolepis canadensis from Miguasha (eastern Canada) is classically considered one of the best-known species. Bothriolepis canadensis was originally described by Whiteaves (1880) based on a few flatten and slightly disarticulated specimens. After the discovery of a couple of dozen specimens of $B$. canadensis primarily preserved in 3D, Patten (1904) published the first reconstruction (Figure 1.1; Patten, 1904, figure 1). In 1948, Stensiö published the most popular reconstruction of $B$. canadensis (Figure 1.2; Stensiö, 1948, text-figure 38) based on abundant material. In his exhaustive monograph on the Bothriolepididae, Stensiö (1948) provided a detailed description of the complete anatomy of this species, which became the reference for numerous studies on Bothriolepis (e.g., Long, 1983; Vézina, 1996; Johanson, 1998, 2002; Thomson and Thomas, 2001; Arsenault et al., 2004; Molochnikov, 2008; Young, 2010; Goujet, 2011). In his revision of the placoderms from the Escuminac Formation, Vézina (1996, figure 1) provided a reconstruction of $B$. canadensis (Figure 1.3), modified from Stensiö, in which a single dorsal fin was figured. More recently, Arsenault et al. (2004, figure 7) proposed a new reconstruction (Figure 1.4) based on two specimens preserved in 3D showing little taphonomic distortion. As of today, Arsenault et al.'s (2004) reconstruction of $B$. canadensis stands as the most accurate one. Even if abundant well-preserved and articulated specimens are available in museum collections around the world (Parent and Cloutier, 1996), part of the external anatomy of $B$. canadensis is still misinterpreted. All these reconstructions were performed using standard 2D projections based on drawings.

Non-invasive technologies such as CT-scan, traditional and synchrotron-based micro-CT-scan are gaining in popularity for quantitative visualiza- tion of fossilized anatomical structures and ultrastructures. However, most studies in virtual paleontology are performed on a limited number of specimens owing to the cost of utilisation and the time required for image acquisition, processing, and interpretation. Usage of such technologies can also be limited by the taphonomic condition and size of the fossil, as well as the type of matrix surrounding the specimen. However, 3D reconstruction of taxon does not necessarily require histological and ultrastructural investigation. Noninvasive 3D laser surface scanner provides the possibility to acquire high-definition surfacescanned images of prepared specimens without the potential limitations imposed by other technologies. The use of 3D digitisation to create virtual models is becoming an efficient method to reconstruct and investigate fossils (Lyons et al., 2000; Gunz et al., 2009; Falkingham, 2012; Molnar et al., 2012; Araújo and Polcyn, 2013), ichnofossils (Bates et al., 2008; Adams et al., 2010; Remondino et al., 2010; Falkingham, 2012; Bennet et al., 2013) and cultural artefacts (Falkingham, 2012; Neamtu et al., 2012).

The Musée d'histoire naturelle de Miguasha (Québec, Canada) houses the largest collection of Bothriolepis canadensis in the world with 3551 specimens (out of 7260 specimens) ranging from 5 $\mathrm{mm}$ to $22 \mathrm{~cm}$ of armor length (Parent and Cloutier, 1996, table 4; Cloutier et al., 2011); however, only ca. $40 \%$ of these specimens have been prepared or do not require preparation. Approximately $15 \%$ of the specimens have a complete dermal armor well preserved with articulated pectoral fins. Approximately $15 \%$ of the specimens are preserved in three dimensions with certain degrees of taphonomic flattening according to sediment compaction (ca. $90 \%$ of the specimens are preserved in laminites). A few specimens show the posterior part of the body preserved as pseudomorphing (Cloutier, 2013).

The main objective of this study was to rebuild a 3D modeling of the Devonian placoderm Bothriolepis canadensis and to validate functional hypoth- 


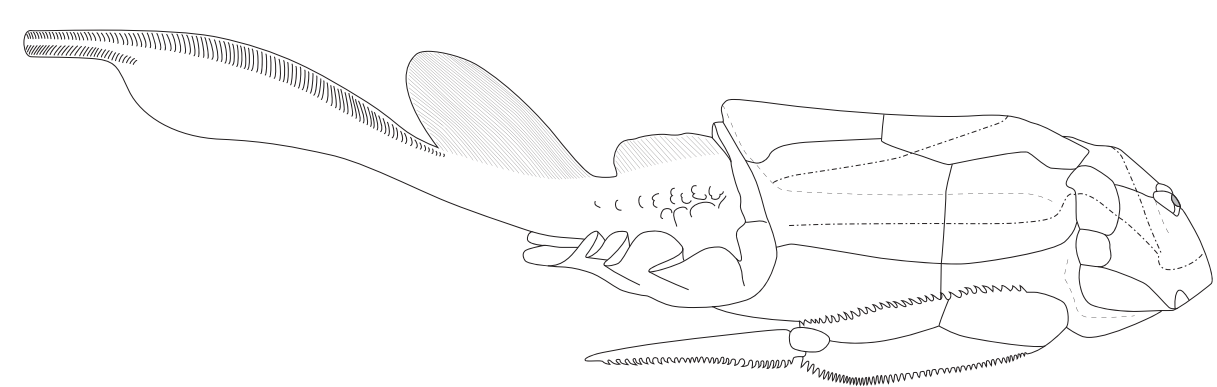

2

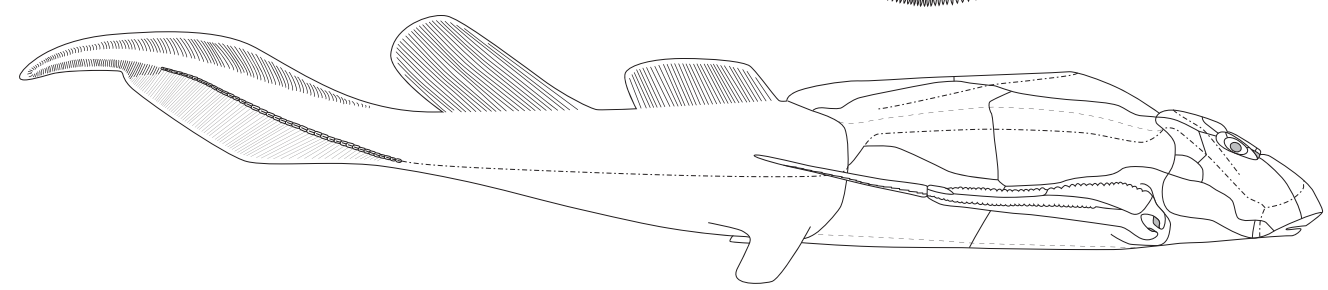

3

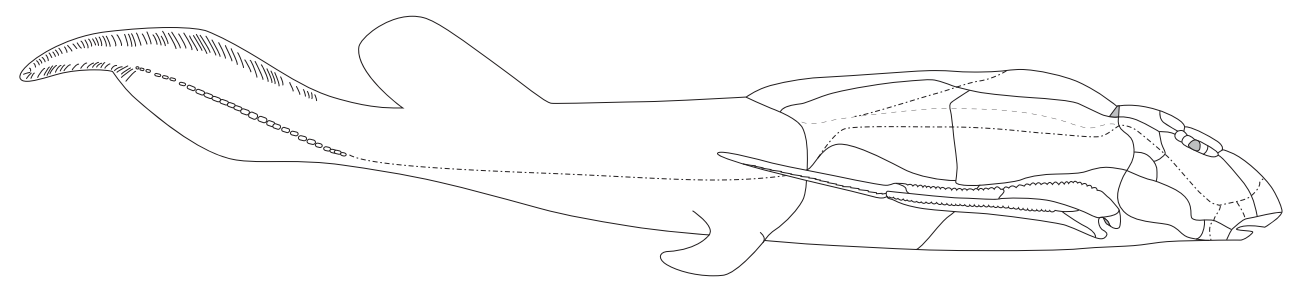

4

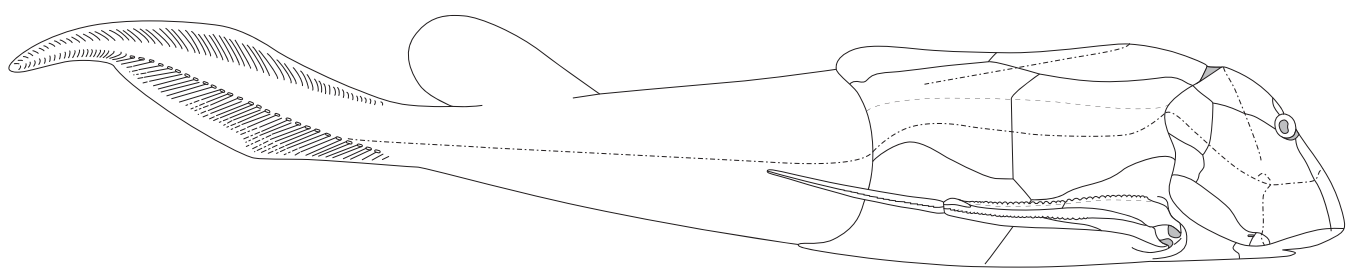

5

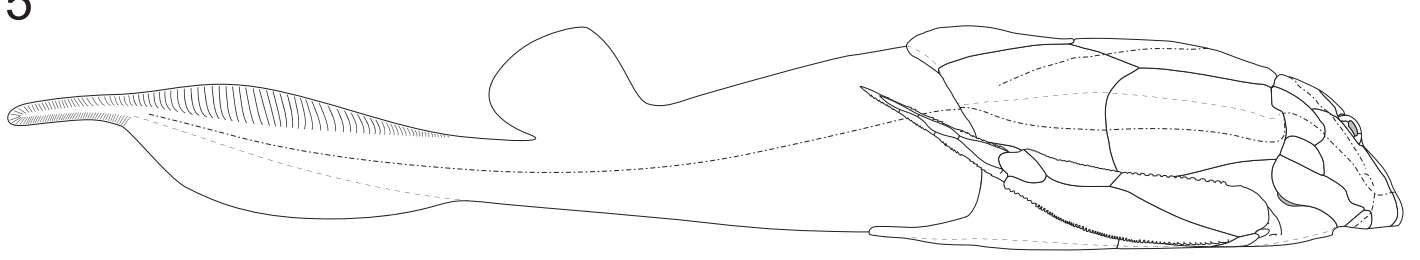

FIGURE 1. Reconstructions of Bothriolepis canadensis: 1.1, redrawn from Patten (1904, figure 1); 1.2, redrawn from Stensiö (1948, text-figure 38); 1.3, redrawn from Vézina (1996, figure 1); 1.4, redrawn from Arsenault et al. (2004, figure $8 \mathrm{C}-8 \mathrm{D}) ; 1.5$, new reconstruction based on $3 \mathrm{D}$ model. Alignment and scaling based on the dorsal thoracic armor length.

eses based on the new reconstruction. The 3D modeling of $B$. canadensis was performed using cutting edge instrumentation in digital imagery including CT-scan, 3D laser scanner and 3D computer graphic softwares.

\section{MATERIAL AND METHODS}

All specimens of Bothriolepis canadensis come from the middle Frasnian Escuminac Formation (Québec, Canada) (Cloutier et al., 1996); $B$. canadensis come from different stratigraphic horizons throughout the formation (Cloutier et al., 2011). The collection of the Musée d'Histoire naturelle de Miguasha (MHNM) was surveyed to select 39 specimens. Specimens were surfacescanned using the Creaform VIUscan 3D scanner. Calibration of the 3D scanner was done using a calibration plate. Configuration of the 3D scanner was done in the data acquisition and processing software VXelements 64 bits v1.1 sr1 build 1150. 
Exposition and laser power were adjusted depending on the color, texture and light peculiarity of the fossils. For data acquisition, volume size was set between 100 and $170 \mathrm{~mm}$, resolution was set to high and the precision varied from 0.2 to $0.33 \mathrm{~mm}$. Fossils were placed on a marker plate and markers were positioned on the matrix surrounding the specimens. Scanned data of the fossils were processed and cleaned up in VXelements software. The marker plate and the scanning artifacts were manually and automatically removed. Markers were removed using an automatic hole capping tool.

Data were exported in a Wavefront OBJ file format to the digital sculpture software ZBrush $4 \mathrm{r} 4$ for modeling work. 3D images of the fossils were reassembled and merged using Zbrush 4 r4 software's advanced features. Zbrush's Dynamesh tool was use to simplify the mesh density, to close gaps and merge objects without losing any details. The TransPose tool was used to transform complete objects or sections of objects using a precise digital ruler. Spotlight tool was used to add details to meshes with floating pictures. Additional tools (e.g., masking, mesh projection, sculpting brushes) were also used.

The scanned data of 19 specimens was used to reconstruct the anterior part of the body (MHNM $02-100,02-149, \quad 02-226,02-423,02-1432,02-$ 1543 , 02-1561, 02-1976, 02-2116, 02-2212, $02-$ $2708,02-2753,02-3173,02-3200,02-3376,02-$ $3461,02-3506,02-3654,02-3802$ ). Time for laser scanning is evaluated from 30 to 60 minutes per specimen, for a total of 15 hours for the 19 specimens. High resolution pictures of four specimens were also used for the reconstruction of the postarmor anatomy (MHNM 02-18B-C, 02-287, 022091A-B, 02-2676). High resolution pictures were taken using a digital camera Nikon D-300.

Because the 3D laser scanning method relies solely on the external morphology, one complete specimen was CT-scanned to validate the internal morphology. Specimen MHNM 02-2676 was CTscanned with a medical CT-scanner (Siemens SOMATOM Sensation 64) at the ETE-INRS (Québec) with the following parameters: field of reconstruction $=0.33 \mathrm{~mm}$, slice thickness $=0.6 \mathrm{~mm}$, reconstruction diameter $=170 \mathrm{~mm}$, voltage $=140$ $\mathrm{kV}$, and X-ray tube current $=472 \mathrm{mAs}$.

Linear regressions were performed using $R$ for Mac OS X GUI 1.40-devel Leopard build 64-bit. Anatomical abbreviations: ADL, anterior dorsolateral plate; afd, external articular area of dorsal central plate 2; afv, external articular area of ventral central plate 2; ar3d, external articular area of dorsal central plate 1; ar3v, external articular area of ventral central plate 1; AVL, anterior ventrolateral plate; Cd1-3, dorsal central plate 1-3; Cv1, ventral central plate 1; fvd, articular fovea of dorsal side of distal segment; La, lateral plate; MI3, lateral marginal plate 3; Mm1-2, medial marginal plate 1-2; pal, lateral anconeal process; pam, medial anconeal process; PMG, post-marginal plate; PrL, prelateral plate; SM, submarginal plate.

\section{The Modeling of Bothriolepis canadensis}

The volume of the thoracic armor for the 3D model was based on the latex cast of specimen MHNM 02-2116 (posterior part of a thoracic armor showing only a slight lateral distortion). The alignment between the dorsal and ventral parts of the armor were adjusted by fitting specimen MHNM 02-3200 on the latex cast of specimen MHNM 022116. The dorsal plates of the thoracic armor of specimen MHNM 02-1561 were fitted on top of the previous assemblage (MHNM 02-3200 + 02-2116). The cephalic armor of specimen MHNM 02-1561 was folded down in position using specimen MHNM 02-2212 as a guide for the inclination of the skull roof. All the head plates of specimen MHNM 02-1561 (with the exception of the prelateral plates taken on specimen MHNM 02-3461) were isolated digitally then articulated together in proper position by respecting the outline of each bone in order to complete the modeling of the cephalic armor.

The articulation of the pectoral fins on the anterior ventrolateral plate was reconstructed from specimen MHNM 02-3802 and 02-3654. The proximal part of the pectoral fin was reconstructed using specimen MHNM 02-226 which is an isolated proximal part of a left pectoral fin and specimen MHNM 02-3506, which is a part of an isolated proximal segment of the right pectoral fin. The external articular area of the dorsal central plate 1 and the ventral central plate 1 of the pectoral fin were reconstructed using specimen MHNM 02-149. The marginal spine pattern of the proximal segment of the pectoral fin was modeled from specimen MHNM 02-208. The number of spines on each side of the proximal segments of the pectoral fin was determined using estimates from linear regressions. The distal segment of the pectoral fin was reconstructed using specimen MHNM 02-1432 and 02-1543. The articular fovea of the distal segment of the pectoral fin was reconstructed using specimen MHNM 02-149. The marginal spine pattern of the distal segment of the pectoral fin was modeled from specimen MHNM 02-249. The precise num- 

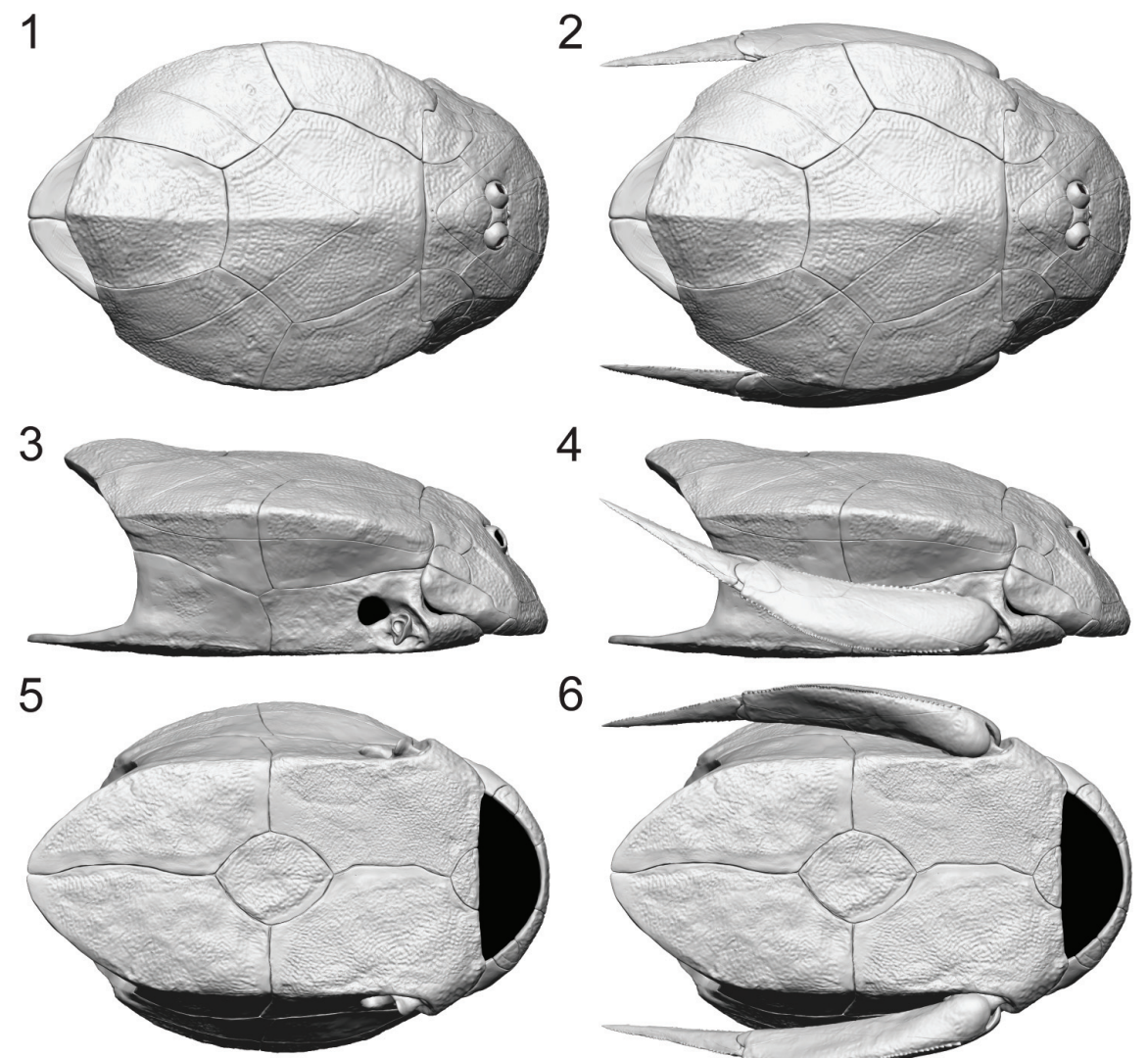

4

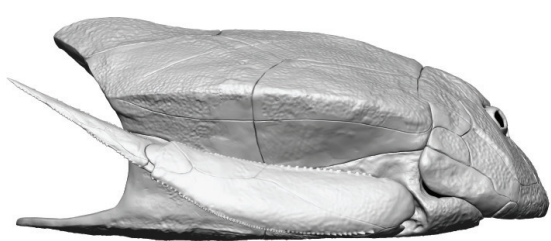

6

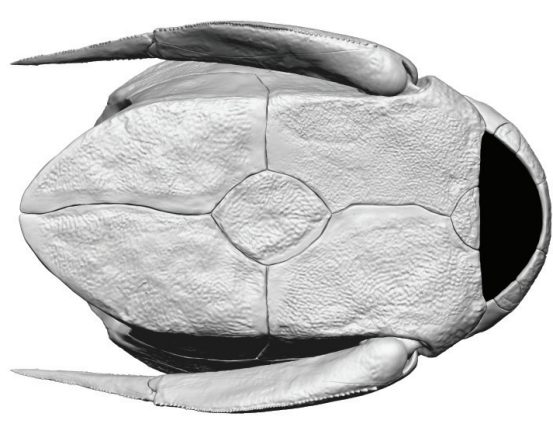

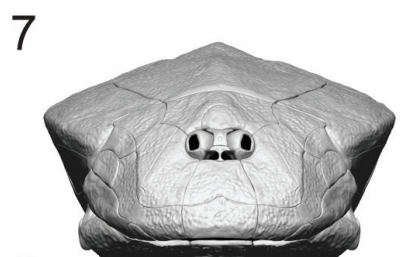

8

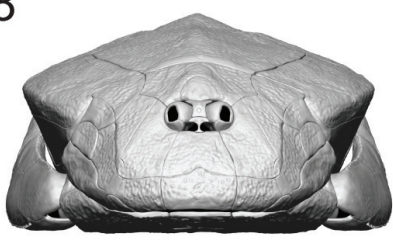

9

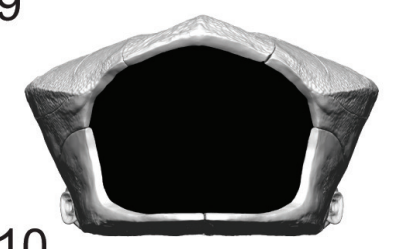

10

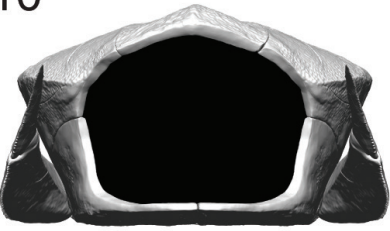

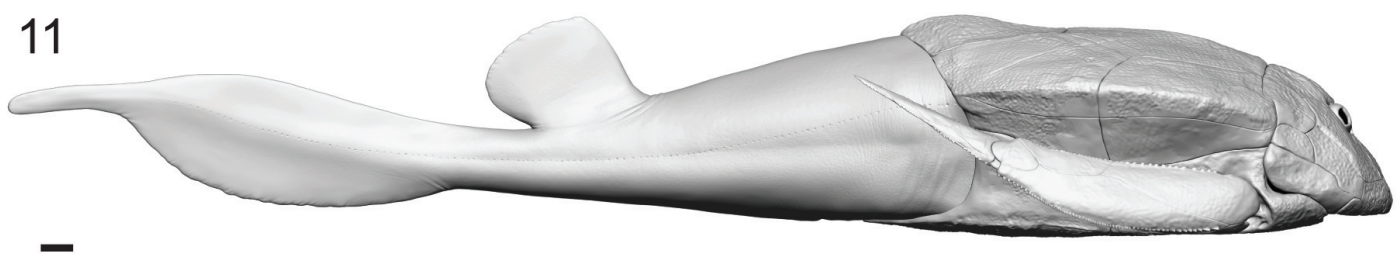

FIGURE 2. 3D reconstruction of Bothriolepis canadensis. Odd numbers without pectoral fins showing the brachial process, even numbers with pectoral fins; 1-2, dorsal view; 3-4 lateral view; 5-6, ventral view; 7-8, front view; 9-10, posterior view; 11, lateral view with posterior part of the body. Scale bar equals $1 \mathrm{~cm}$. Use this figure as a target for the PaleoAR mobile application to get the 3D model.

ber of spines on the lateral side of the distal segment was determined using a linear regression and the number of spines on the medial side was estimated based on similar size specimens. The model of the pectoral fin was then scaled up to fit specimen MHNM 02-1561.

The post-armor anatomy was completely modeled in Zbrush software using images of specimens MHNM 02-2091A-B and 02-2676. The volume of the body at the posterior limit of the armor was based on the latex cast of specimen MHNM 02-2116. Body proportion and median fin position and shape are based on specimen MHNM 022091A-B and 02-2676. The number of fin rays of the epichordal and hypochordal lobes was based on specimen MHNM 02-287, which is the largest well-preserved caudal fin among the specimens of the MHNM collection.

\section{RESULTS}

The 3D modeling of Bothriolepis canadensis is presented in Figure 2 with the corresponding 2D schematic projections in Figure 3 . The estimated total length (estimated TL) of the model fish is $43.67 \mathrm{~cm}$, whereas the estimated length of the dermal armor (from the anterior tip of the cephalic armor to the dorsal posterior margin of the thoracic armor) is $15.53 \mathrm{~cm}$ and covers $35.6 \%$ of the esti- 
1

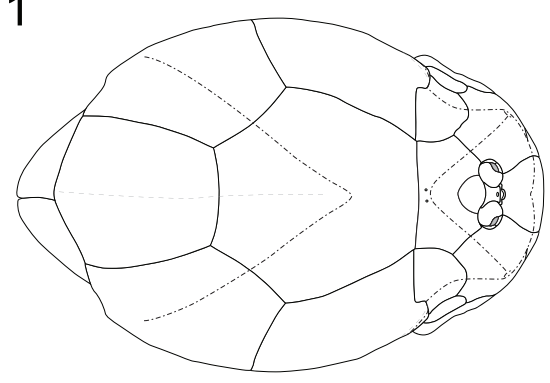

3

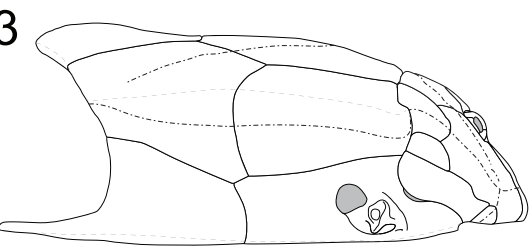

5

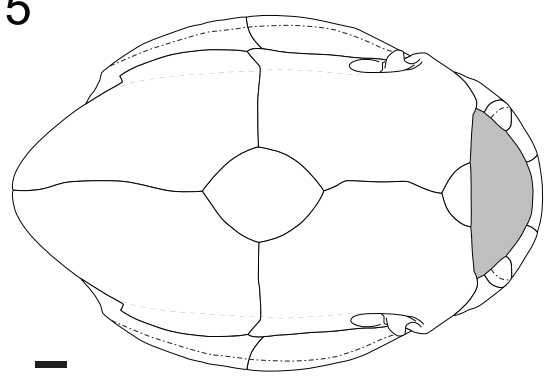

2

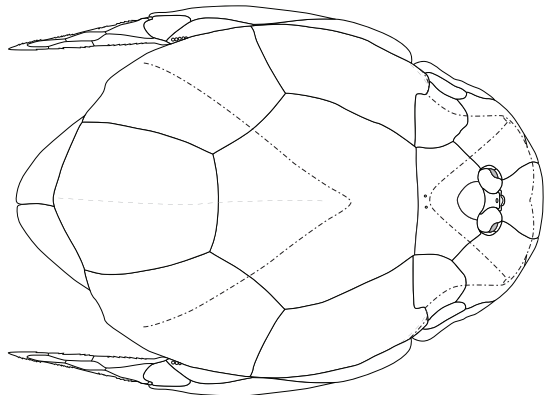

4

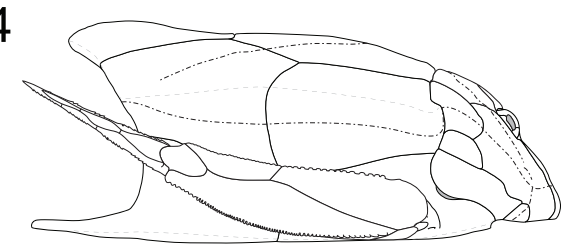

6

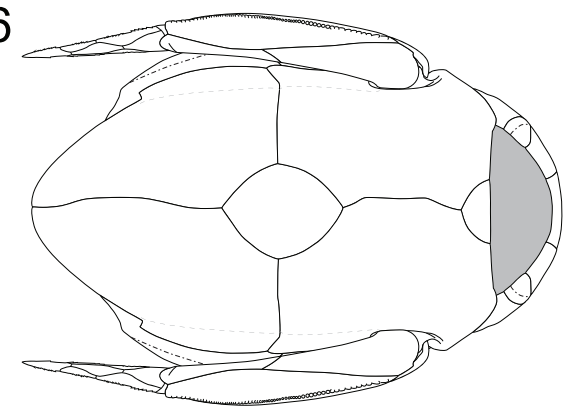

7
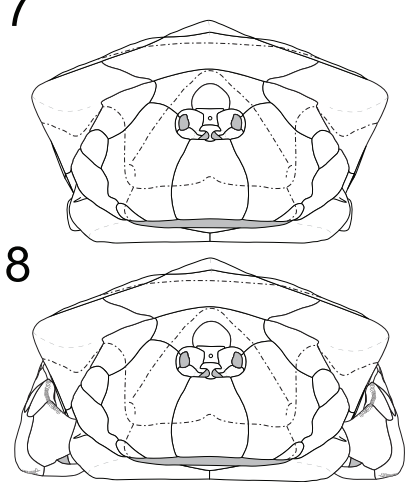

9
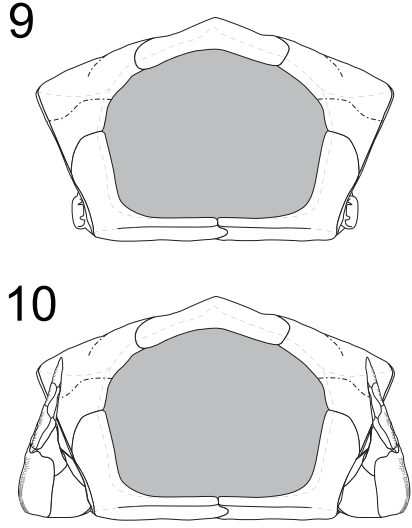

FIGURE 3. New reconstruction of Bothriolepis canadensis. Odd numbers without pectoral fins showing the brachial process, even numbers with pectoral fins; 1-2, dorsal view; 3-4 lateral view; 5-6, ventral view; 7-8, front view; 9-10, posterior view. Scale bar equals $1 \mathrm{~cm}$.

mated TL. This reconstruction is valid for a large adult specimen (Cloutier et al., 2009) since allometric changes have been documented in a size series of $B$. canadensis (Werdelin and Long, 1986).

\section{Cephalic Armor}

The cephalic armor represents $26.5 \%$ of the dermal armor length and $9.3 \%$ of the estimated TL. The proportion of the cephalic armor in relation to the dermal armor length differs among reconstructions [27.8\% (Patten, 1904), 30\% (Stensiö, 1948), 33\% (Vézina, 1996), and 34.7\% (Arsenault et al., 2004)]. The lower cephalic proportion is most likely related to the stepper inclination. The skull roof is steeply inclined making an angle of $64^{\circ}$ with the ventral floor of the head which differs from previous reconstructions $\left[80^{\circ}\right.$ (Patten, 1904), 36 ${ }^{\circ}$ (Stensiö, 1948), $35^{\circ}$ (Vézina, 1996) and $58^{\circ}$ (Arsenault et al., 2004)]. There should be no difference in the angle of inclination between Arsenault et al.'s (2004) reconstruction and the $3 \mathrm{D}$ model because both reconstructions are based on the same reference specimen (MHNM 02-2212). This difference might result from a greater precision when using 3D scanning and modeling.

The shape of the postero-dorsal margin of the cephalic armor (composed of the nuchal, paranuchal, postmarginal, submarginal and prelateral plates) fits perfectly with that of the antero-dorsal margin of the thoracic armor (composed of the anterior median dorsal, anterior dorsolateral and anterior ventrolateral). The submarginal plate fits with the anterior ventrolateral plate except for the posterior margin of the submarginal which is occupied by the gill opening (Figure 4). The cephalic armor is immobilized upon the thoracic armor.

The presence of a nuchal gap (Stensiö, 1948; Arsenault et al., 2004) and the interpretation of a possible head movement (Stensiö, 1948, text-figure 5; Young, 1984; Young and Zhang, 1992) are not supported by the present study. The 3D model of the cephalic armor has a perfect fitting for the nuchal plate with the anterior median dorsal plate. 


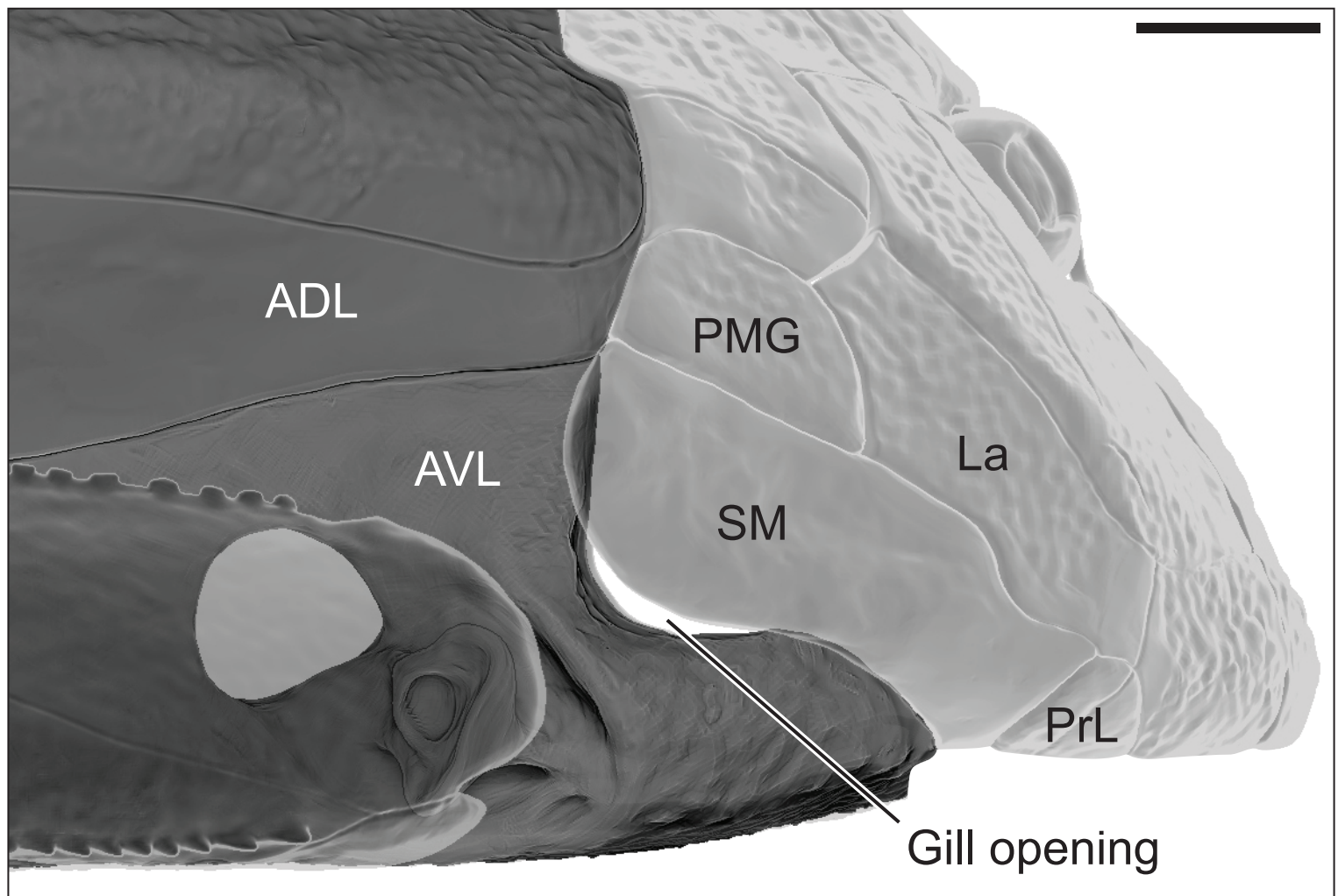

FIGURE 4. Gill opening of Bothriolepis canadensis. Head plates and pectoral fin in transparency to illustrate the relationships between the anterior ventrolateral plate (AVL) and the submarginal plate $(\mathrm{SM})$.

This perfect fitting does not allow for up-and-down and lateral movements of the head. Furthermore, CT-scan data of specimen MHNM 02-2676 show clearly that the cephalic armor abuts tightly against the well-developed vertical part of the anterior crista transversalis interior of the anterior dorsal and ventral lateral plates.

The submarginal plate fits perfectly with surrounding cephalic (post-marginal, lateral and prelateral plates) and thoracic plates (anterior ventrolateral and anterior dorsolateral plates). The submarginal plate is tightly connected to the lateral plate (contra Stensiö, 1948). In ventral view (Figure 2.5-6), the tight fitting of the submarginal plate between the anterior ventrolateral plate and the prelateral plate does not let place for movement. A gill opening is present between the postero-ventral margin of the submarginal plate and the anterior margin of the anterior ventrolateral plate (Figure 4). Below the gill opening, the submarginal plates fit perfectly between the anterior ventrolateral plates and the prelateral plates supporting the impossibility of movement for the submarginal plates (contra Stensiö, 1948; Watson, 1961; Young, 1984). The gill opening of Bothriolepis canadensis is restricted to a space behind the submarginal plate rather than an opening behind and below the "gill cover" (Stensiö, 1948, Text-figure 4). As described for Bothriolepis sp. from Gogo (western Australia; Young, 2008), the gill opening is bounded posteriorly by a deep notch in the anterior margin of the anterior ventrolateral plate. The notch is clearly visible in contrast to previous reconstructions.

Two specimens (MHNM 02-3461 and 023541) show anatomical features that could be related potentially to a spiracle; in both specimens, a groove on the anterior margin of the submarginal plate is located in a similar position than previously described in Bothriolepis macphersoni (Young and Zhang, 1992) and B. panderi (Watson, 1961). Stensiö (1948) mentioned that some specimens did not have spiracle, whereas Myers (1942) pointed out that there was no spiracle. The position of the spiracle identified by Stensiö (1948) is not corroborated by the present study. Since the presence of a spiracle has not been unambiguously observed, a spiracle has not been included in the 3D model.

A complete reconstruction of the mouth area was not possible. The mental plates are preserved only on a few prepared MHNM specimens where 
only three specimens could be scanned properly (MHNM 02-2708, 02-3376 and 02-3461). The inferognathal bones, the submandibular and subhyoidal series are preserved only on specimen MHNM 021037 and the infraprelateral is partly preserved only on specimen MHNM 02-3502A-B. The poor state of preservation of these elements and their small size prevented from capturing them with the $3 \mathrm{D}$ scanner. However, the reconstruction of the area surrounding the mouth with the head in its accurate inclination gave a much smaller area than the one presented by numerous authors (Stensiö, 1948; Young, 1984; Janvier, 1996).

\section{Thoracic Armor}

The new reconstruction of the thoracic armor of Bothriolepis canadensis shows that the armor is pentagonal in cross-section with a clear posterior dorsal apex formed by a dorsal median crest. The dorsal part of the armor is convex delimited by dorsal lateral keels. The lateral sides are slightly concave and also delimited ventrally by ventral lateral keels. The ventral side is flat.

The ventral part of the thoracic armor (from the anterior margin of the semilunar plate to the posterior limit of the posterior ventrolateral plate) is 1.25 time longer than the dorsal part of the thoracic armor (from the anterior margin of the anterior median dorsal plate to the posterior margin of the posterior median dorsal plate). The median dorsal ridge forms a hydrodynamic dorsal crest with its maximum height along the posterior median dorsal plate (Figures 2.3-4, 2.7-11, 3.3-4, 3.7-11). The height of the thoracic armor at mid-length of the mixilateral plate $(6.66 \mathrm{~cm})$ is $15.25 \%$ of the estimated TL. The length of the mixilateral plate at the dorsolateral angle $(4.71 \mathrm{~cm})$ is $10.79 \%$ of the estimated TL. The ratio of the height of the thoracic armor (measured at mid-length of the mixilateral plate) on the length of the mixilateral plate (measured on the dorsoventral angle) is 1.41 [1.13 (Patten, 1904; Stensiö, 1948), 1.56 (Arsenault et al., 2004)]. The ratio obtain for the 3D model was expected to be the same as that of Arsenault et al. (2004), because both reconstructions used specimen MHNM 02-2116 as a reference for the body volume. Measurements on specimen MHNM 022116 differ between the two reconstructions: the height of the thoracic armor of the 3D model is 6.66 $\mathrm{cm}$ contra $7.5 \mathrm{~cm}$ (Arsenault et al., 2004) and the length of the mixilateral plate at the dorsolateral angle is $4.71 \mathrm{~cm}$ contra $4.8 \mathrm{~cm}$ (Arsenault et al., 2004). Arsenault et al. (2004) mentioned that their ratio was not representative of their reconstruction probably due to parallax distortions. However, the ratio measured on their reconstitution (Figure 1.4) is 1.46 (similar to the one from the $3 \mathrm{D}$ model ratio) and the difference with their calculated ratio is caused by an inaccurate measurement on the thoracic armor rather than parallax distortion. For a same thoracic armor length, the height of the thoracic armor of Patten's (Figure 1.1) reconstruction is higher than Stensiö's (Figure 1.2) but the mixilateral plate is also longer than in any other reconstructions. The accuracy of this ratio is highly questionable on its emplacement along the body but also on an animal that grew allometrically.

The body shape obtained in the present study is similar to that suggested by Patten (1904) and Arsenault et al. (2004). The crest formed by the median dorsal ridge at the posterior limit of the posterior median dorsal plate is higher than it was previously described (Figures 1.2-3; Stensiö, 1948; Vézina, 1996). Stensiö (1948) described the median dorsal ridge of Bothriolepis canadensis to be very low and flat, whereas Vézina (1996) described the trunk armor to be long and low. The lateral dorsal profile differs from that reconstructed by Arsenault et al. (2004) even if the same two specimens were used. The reconstruction of Arsenault et al. (2004, Figure 1.4), while not as flat as described by Stensiö (1948), is still too low. In Arsenault et al. (2004), the height of the body was mainly based on specimen MHNM 02-2116 combined with observations on specimen MHNM 022212. Both specimens were buried perpendicular (MHNM 02-2116) or slightly oblique (MHNM 022212) to the stratigraphy showing no dorso-ventral compression. Specimen MHNM 02-2212 is a cephalic and thoracic armor showing minor anteroposterior distortion, and even though the head is compressed on the left side, it still shows its actual inclination. The reconstruction methods that we used permitted us to correct for taphonomic distortion. Furthermore, an additional problem using those two specimens is the difference in body size and shape. Specimen MHNM 02-2116 is a large specimen $(15.53 \mathrm{~cm}$ of estimated dermal armor length) in contrast to MHNM 02-2116 that is a small-medium size specimen (ca. $8.74 \mathrm{~cm}$ of dermal armor length).

\section{Pectoral Fins}

The pectoral fin length corresponds to $30.5 \%$ of the estimated TL (Figure 5). The proximal segment (Figure $6.1-3$ ) represents $63.6 \%$ of the pectoral fin length, whereas the distal segment (Figure $6.4-5$ ) represents $36.4 \%$. Because the number of 

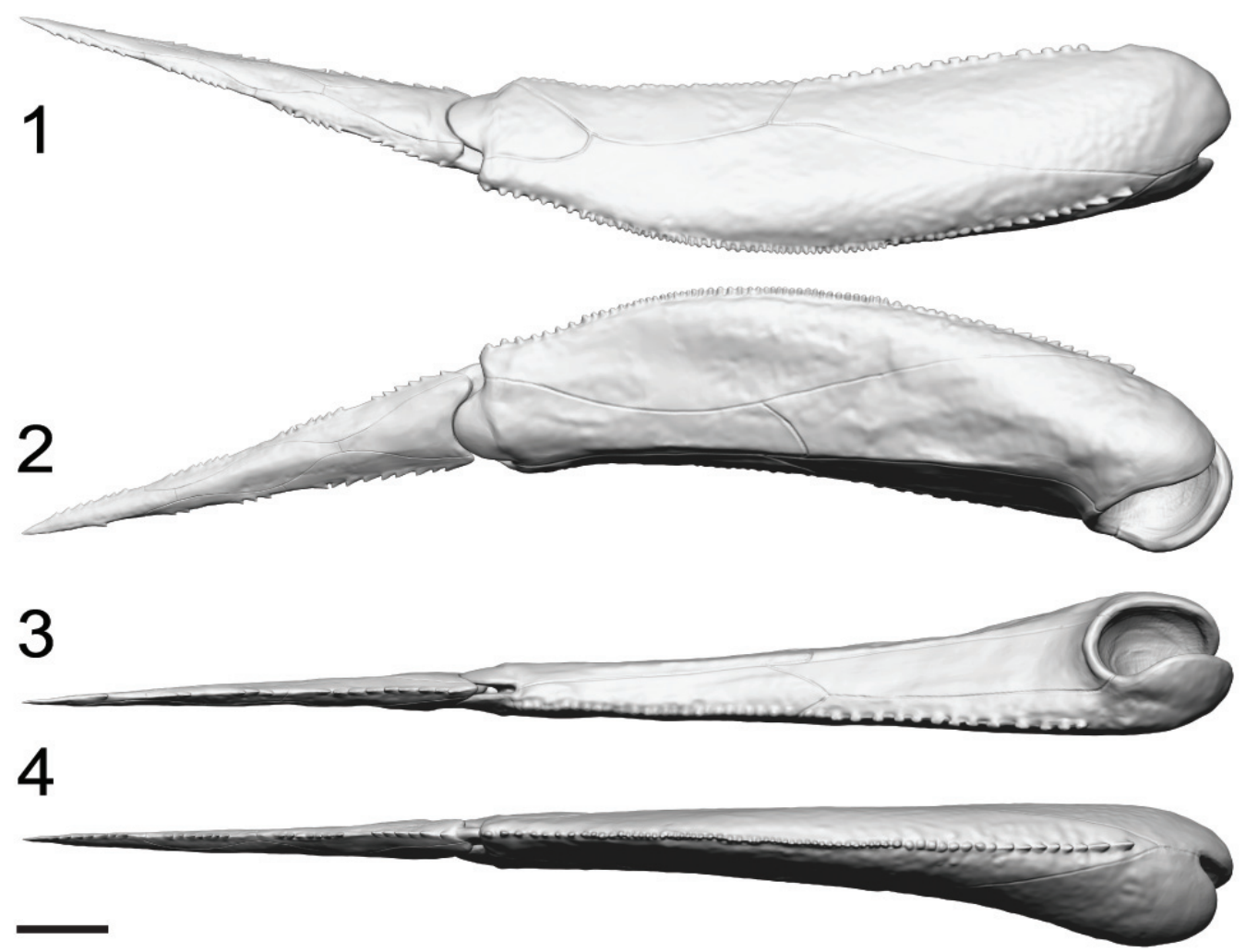

FIGURE 5. 3D reconstruction of the right pectoral fin of Bothriolepis canadensis: 1, lateral view; 2, medial view; 3, ventral view; 4 , dorsal view. Scale bar equals $1 \mathrm{~cm}$.

pectoral fin spines is increasing with size, linear regressions were used to estimate the accurate number of spines represented on the 3D model (Table 1). The proximal segment of the pectoral fin includes 64 lateral spines and 40 medial spines. Even if the medial spines regression is not significant $(p=0.23)$, the number of 40 medial spines was kept because it was consistent with the number of spines observed on specimens of similar size. The distal segment of the pectoral fin includes 27 lateral spines and 15 medial spines (number estimated).

The 3D model of the pectoral fin and associated brachial process allowed us to validate the possible range of movements by the pectoral fin by virtual manipulations (Figure 7). Protraction (abduction), retraction (adduction), rotation and upand-down movement of the pectoral fin were evaluated by digital manipulation of the 3D model. The fully retracted position of the pectoral fin is shown in figures 2.2, 2.4, 2.6, 2.8, 2.10, 2.11; this position allows a rotation of $5^{\circ}$ around the brachial process (Figure 7.1). When fully retracted, there is no upand-down movement possible on the brachial process. The maximum angle of protraction is $70^{\circ}$
(Figure 7.2-3). When fully protracted, the fin cannot rotate around the brachial process nor do an upand-down movement. The maximum mobility of the fin is given by an angle of protraction around $16^{\circ}$ (Figure 7.5). At this angle, the fin can move $32^{\circ}$ around the brachial process (Figure 7.6) and can do an up-and-down movement of $15^{\circ}$ (Figure 7.7). The distal segment of the pectoral fin can move in a latero-medially angle of $45^{\circ}$ (Figure 1.4). Most of the observations made for the pectoral fin movements in the present study support previous observations made by Young and Zhang (1992). The acid-prepared material of Bothriolepis sp. from Gogo allowed Young and Zhang (1992) to manipulate the pectoral fin on the brachial process just like it was possible to virtually manipulate the 3D model.

The position of pectoral fins illustrated in previous reconstructions of Bothriolepis canadensis [and other Bothriolepis species inspired from $B$. canadensis] is anatomically inaccurate (Patten 1904; Stensiö, 1948; Long, 1983; Vézina, 1996; Janvier 1996; Arsenault et al., 2004). This inaccuracy is likely owing to the usual taphonomic displacement of the pectoral fins in relation with the 

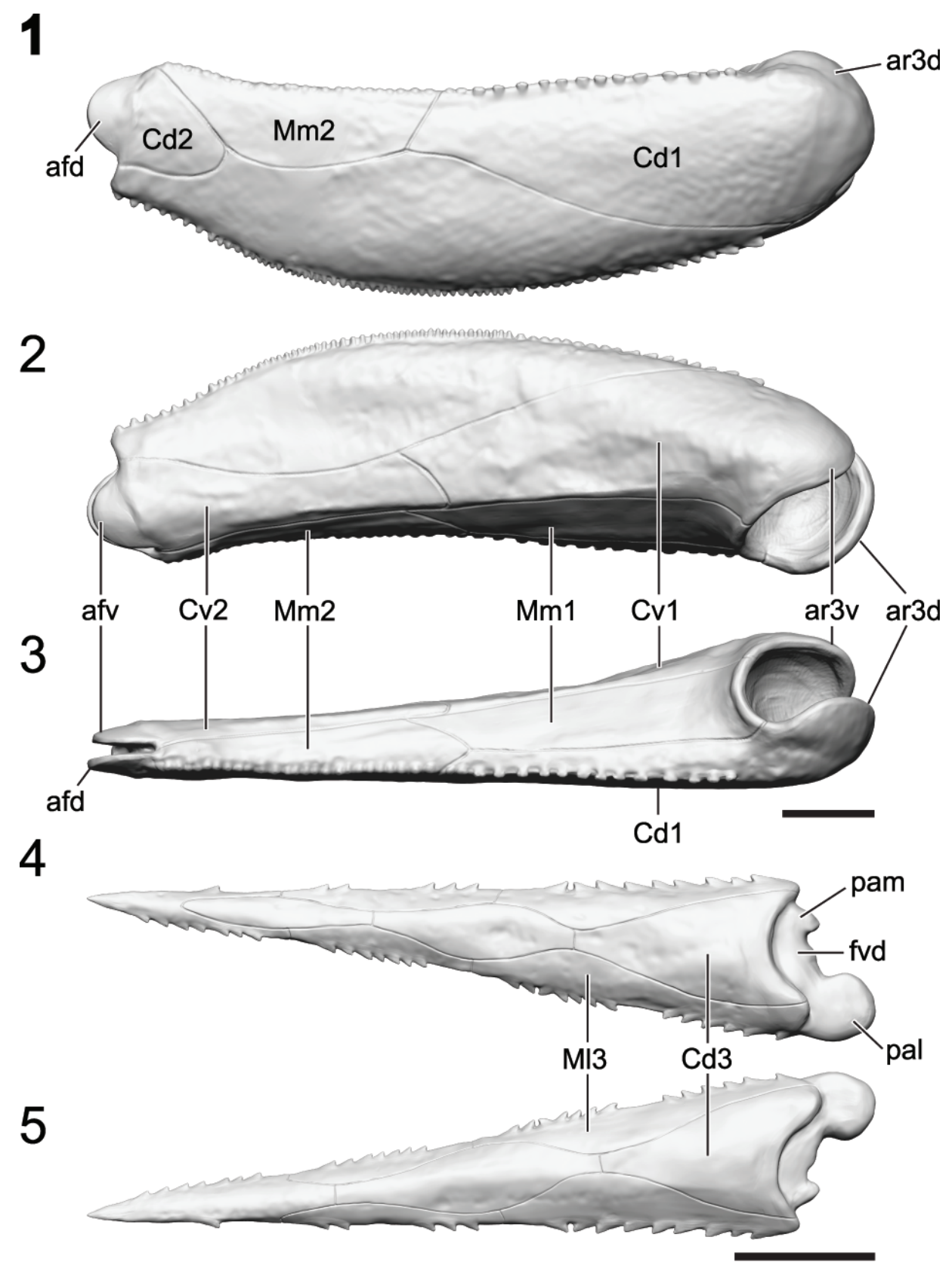

FIGURE 6. 3D reconstruction of the right pectoral fin segments of Bothriolepis canadensis: 1, lateral view of proximal segment; 2, medial view of proximal segment; 3, ventral view of proximal segment; 4, lateral view of distal segment; 5 , medial view of distal segment. Scale bar equals $1 \mathrm{~cm}$.

TABLE 1. Linear regression of the number of pectoral fin spines related to length of the pectoral fin segment of Bothriolepis canadensis. * $p<0.05$

\begin{tabular}{ccccccc}
\hline Fin segment & Position & $\mathbf{n}$ & Equation & $\mathbf{R}^{\mathbf{2}}$ \\
\hline proximal & lateral & 39 & number of spines $=0.54^{*}$ (proximal segment length) $+19.6682 \pm 0.04$ & $1.65 \mathrm{e}-14^{*}$ & 0.79 \\
proximal & medial & 8 & number of spines $=0.09{ }^{*}$ (proximal segment length) $+32.08 \pm 0.07$ & 0.23 & 0.10 \\
distal & lateral & 11 & log number of spines $=30.42{ }^{*}$ (log distal segment length) $-24.79 \pm 8.26$ & $0.005^{*}$ & 0.56 \\
\hline
\end{tabular}




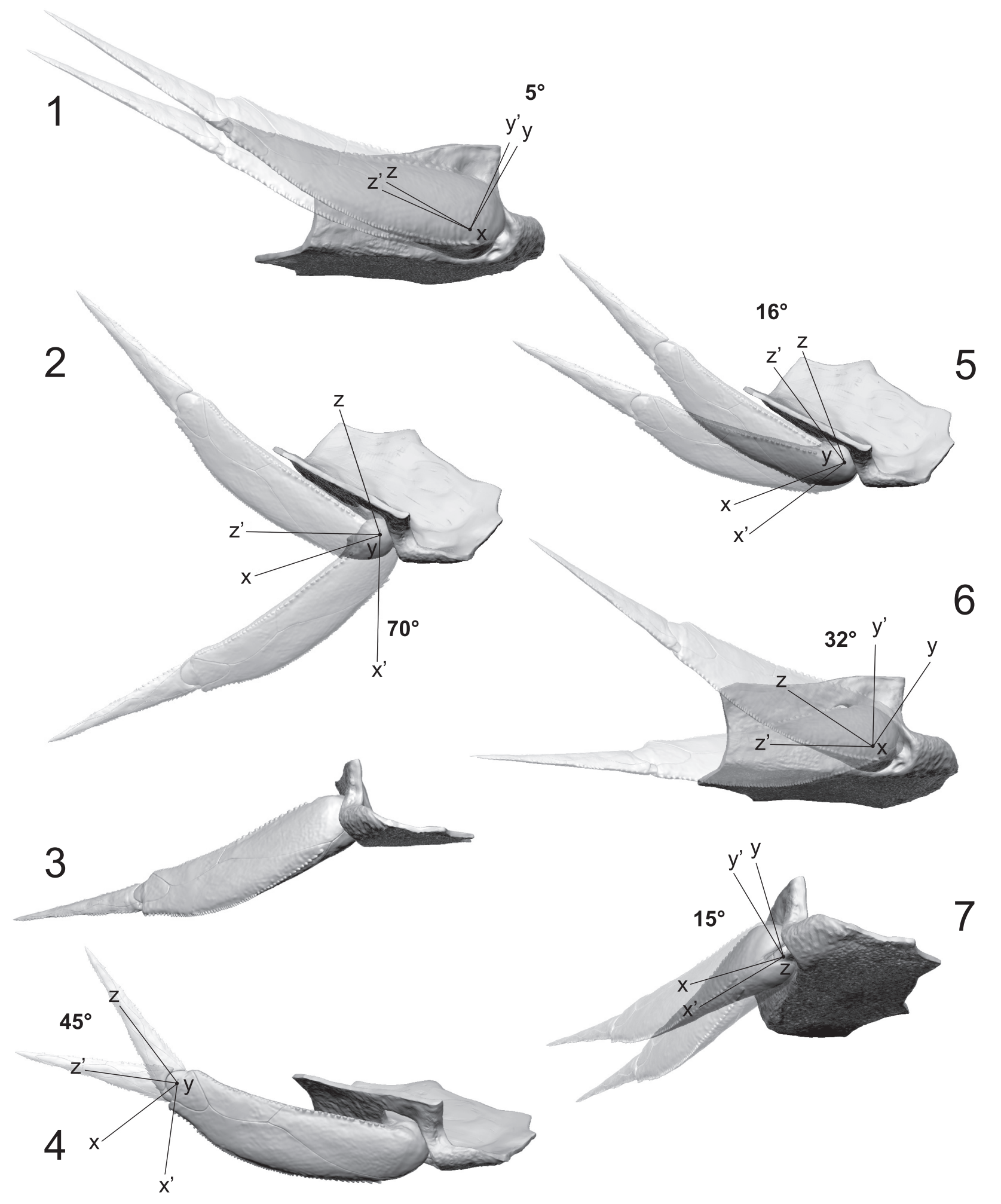

FIGURE 7. Range of movements for the pectoral fin of Bothriolepis canadensis: 1, rotation around the brachial process in fully retracted position; 2, fully protracted position; 3, fully protracted position front view; 4, latero-medially movement of the distal segment; 5 , minimum angle of protraction for maximum mobility of the pectoral fin; 6 , rotation around the brachial process in a protracted angle of $16^{\circ} ; 7$, up-and-down movement in a protracted angle of $16^{\circ}$. Use this figure as a target for the PaleoAR mobile application to get a video of pectoral fins possible movement range. 
trunk. The only way to position the pectoral fin like Patten's (1904) reconstruction, the pectoral fin has to be protracted at a minimum angle of $16^{\circ}$. With regard to position of the pectoral fin in Stensiö's (1948) and Arsenault et al.'s (2004) reconstructions, it is impossible without disarticulating the fin or fracturing the brachial process through the anterior ventrolateral plate.

\section{Trunk and Median Fins}

The posterior part of the body is longer than reported previously (Figure 1). Anal and pelvic fins are absent. The vertebral column shows no trace of ossification. The trunk and caudal fin are scaleless.

A single dorsal fin lacking fin rays is present. Vézina (1996, figure 1) was the first to reconstruct Bothriolepis canadensis [modifying Stensiö's (1948) reconstruction] with a single dorsal fin (Figure 1.3). The dorsal fin of $B$. canadensis is square shape (Figure 1.5) rather than oval (Figure 1.1; Patten, 1904), rectangular (Figure 1.2; Stensiö, 1948) or rounded (Figure 1.4; Arsenault et al., 2004). The insertion of the dorsal fin is located at $54.5 \%$ of the estimated TL, while the length at the base corresponds to $7.9 \%$ of the estimated TL. This mid-length position of the dorsal fin differs from the anterior position of the dorsal fin represented in some reconstructions (Janvier, 1996, figure 4.52; Moloshnikov, 2008, figure 2a).

The length of the caudal fin represents $34.6 \%$ of the estimated TL (Figures 1.5, 2.11). The insertion of the epichordal lobe is at $65.5 \%$ of the estimated TL, whereas the insertion of the hypochordal lobe is at $68.1 \%$ of the estimated TL. Based on specimens MHNM 02-2091A-B, 02-2676 and $02-287$, the epichordal lobe of the caudal fin is low. The epichordal lobe includes between 118 and 137 pairs of closely-spaced and gently-curved posteriorly fin rays (MHNM 02-18B, 02-287, 02-2676, 02-3407), whereas the condition varies along the hypochordal lobe. The number of caudal fin rays is based on specimen MHNM 02-287 which is 137 pairs for the epichordal lobe and 47 pairs for the hypochordal lobe. Dorsally, the fin rays are limited to the epichordal lobe of the caudal fin and do not reach the dorsal fin (contra Patten, 1904; Figure 1.1). Only the narrow terminal part of the hypochordal lobe includes between 36 and 47 pairs of fin rays (MHNM 02-18B, 02-287, 02-2676), whereas no fin rays were observed in the deepest part of the hypochordal lobe. Arsenault et al. (2004) considered that caudal fin rays of the hypo- chordal lobe of specimen MHNM 02-2091A were absent. However, hypochordal fin rays are clearly visible on the counterpart (MHNM 02-2091B). In contrast to Arsenault et al. (2004), there are no rays along the main hypochordal lobe. In all previous descriptions of the fin rays, there has never been a mention that these structures are paired.

A darker linear area is visible along the ventral side of the chordal lobe but no scales were observed. This area was interpreted as a row of small scales by Stensiö (1948, text-figure 62 A-C) and Arsenault et al. (2004). Water immersion of three specimens (MHNM 02-18B-C, 02-2091 and 02-2676) revealed a darker area of preserved organic matter. This preservation of organic matter is similar to the corresponding position of the notochord on larval and juvenile specimens of the dipnoan Scaumenacia curta (Béchard and Cloutier in prep.); it is interpreted similarly in Bothriolepis canadensis.

\section{New Two-dimensional Reconstructions}

The 3D model of Bothriolepis canadensis was used to generate two-dimensional views (Figure 3). Based on these representations, it is clear that the classical, dorsal and lateral views of $B$. canadensis with the head completely flatten and the pectoral fins extended are inaccurate. In contrast to previous reconstructions, the actual size and shape of cephalic elements are respected (Figure 1). The size and shape of the cephalic plates obtain with the 3D model are more similar to the reconstruction of Stensiö (1948; Figure 1.2). Most cranial plates from Patten's (1904) reconstruction are too stylized (e.g., see the shape of the submarginal plate, the absence of the premedian plate and of a visible postpineal plate in lateral view). The reconstruction of Arsenault et al. (2004; Figure 1.4) shows several inaccuracies: the submarginal is higher posteriorly, the shape of the postmarginal plate is more rounded, and the lateral plate is narrower.

\section{DISCUSSION}

As pointed out by Young (2010), the morphological condition of antiarch placoderms has frequently been based on the conditions inferred from Bothriolepis canadensis. Thus, it is most important to recognize the correct morphology of this species whether it is for morphological, functional or phylogenetic purposes. The new reconstruction of Bothriolepis canadensis permits to redefine numerous details on the actual body shape of this fish. 


\section{Morphological Considerations}

The different reconstructions of Bothriolepis canadensis differ in terms of body proportions and shape. These differences potentially result from four types of bias: (1) the number of specimens available to reconstruct a typical specimen; (2) the taphonomic distortions of specimens; (3) an improper usage of a combination of specimens of different sizes; and (4) difficulties to represent planar projections from a complex 3D model.

One might expect that the number of specimens available to produce a reconstruction would influence the accuracy. Patten's (1904) reconstruction was based on a relatively low number of specimens. However, most specimens used by Patten came from a single stratigraphic horizon (near the channel; Cloutier et al., 2011) where fossil fishes were buried rapidly preserving soft tissues. In contrast Stensiö (1948) had potential access to 703 specimens from the Naturhistoriska Riskmuseet, Stockholm (Parent and Cloutier, 1996, Table 4). Vézina (1996) modified Stensiö's (1948) reconstruction based on the few specimens of Bothriolepis canadensis with postcranial preservation from the MHNM collection. Arsenault et al. (2004) used primarily two 3D specimens from the MHNM collection. Although we also had access to the largest collection of $B$. canadensis, we laser scanned solely 19 specimens (and used an additional four specimens) out of 3551 specimens to produce the reconstruction. Although the number of specimens is high, only $40 \%$ of them are prepared (or do not need preparation), and of those visible only a few of them are complete and preserved in 3D. Most likely it is not as much the number of specimens than the state of preservation that permits accurate reconstruction. Johanson (1998, p. 317) mentioned that besides the usual taphonomic problems (e.g., distortion, crushing, breakage) consideration of only a small sample of individuals could lead to inaccurate interpretation of the morphology.

With regard to Bothriolepis (as well as most fossils), the preservation of 3D specimens is related to the condition of deposition (Parent and Cloutier, 1996; Cloutier et al., 2011; Goujet, 2011). Specimens of Bothriolepis canadensis have been found in the five Escuminac lithofacies (i.e., conglomerate, sandstone, siltstone, laminate and shale) (Cloutier et al., 2011) but most abundantly in the laminites (including laminated concretions). Most specimens of $B$. canadensis are preserved dorso-ventrally (Parent and Cloutier, 1996) with a certain degree of dorso-ventral compression owing to sediment compaction. Specimens found in sand- stone and siltstone (Figure 8.6-10) are less compressed than those found in laminites and shale (Figure 8.1-5); only disarticulated elements have been found in a conglomeratic layer (Parent and Cloutier, 1996). McAllister (1996) mentioned that there could be up to $50 \%$ of sediment compaction in certain facies based on the deformation of coprolites. We calculated the percentage of compaction based on a ratio taking into account the measured compressed height versus the estimated height of the thoracic armor at the midlength of the anterior median dorsal plate: $41 \%$ (31 to $45 \%$ ) of compaction for specimens of $B$. canadensis $(n=5$, S.D. $=0.06)$ preserved in siltstone, and $70 \%$ (50 to $83 \%$ ) of compaction for specimens in laminites $(n=12$, S.D. $=0.10)$. As far as we know only two specimens have been found perpendicular to the stratigraphy, thus minimizing body deformation owing to sediment compaction. Goujet (2011, p. 327) mentioned that most specimens of $B$. canadensis are fossilized with their ventral side up referring among others to Parent and Cloutier (1996, p. 74). Parent and Cloutier (1996) mentioned effectively that most specimens were preserved ventral side up but in reference to a specific horizon (bed 238), and it was not intended as a general comment on the taphonomy of all specimens of $B$. canadensis from the Escuminac Formation. In the majority of specimens, which are preserved dorsal side up, the dorsal side of the thoracic armor has collapsed longitudinally on each side of the median dorsal plates (as observed by Goujet, 2011) as well as between the anterior median dorsal and posterior median dorsal plates (Figure 8.6-10). Furthermore, the ventral projection of both the anterior dorsolateral and mixilateral plates slided inside the thoraco-abdominal cavity, leaving the dorsal projection of both the anterior and posterior ventrolateral plates standing perpendicular to stratigraphy in coarse sediments (Figure 8.6-10). As mentioned by Goujet (2011) for the 3D fossils from the Wood Bay sandstone of Spitsbergen, the upper half of the specimen is compressed and slightly disarticulated, whereas the lower half remains tridimensional with little alteration of the original animal volume. When preserved ventral side up, the ventral armor has collapsed medially along the mid-line. In both cases, the height of the thoracic armor comes from the ventral projection of the dorsolateral plates (anterior dorsolateral and mixilateral plates) and the dorsal projection of the ventrolateral plates (anterior and posterior ventrolateral plates). This lateral height has frequently been used as an indication of the total armor height 


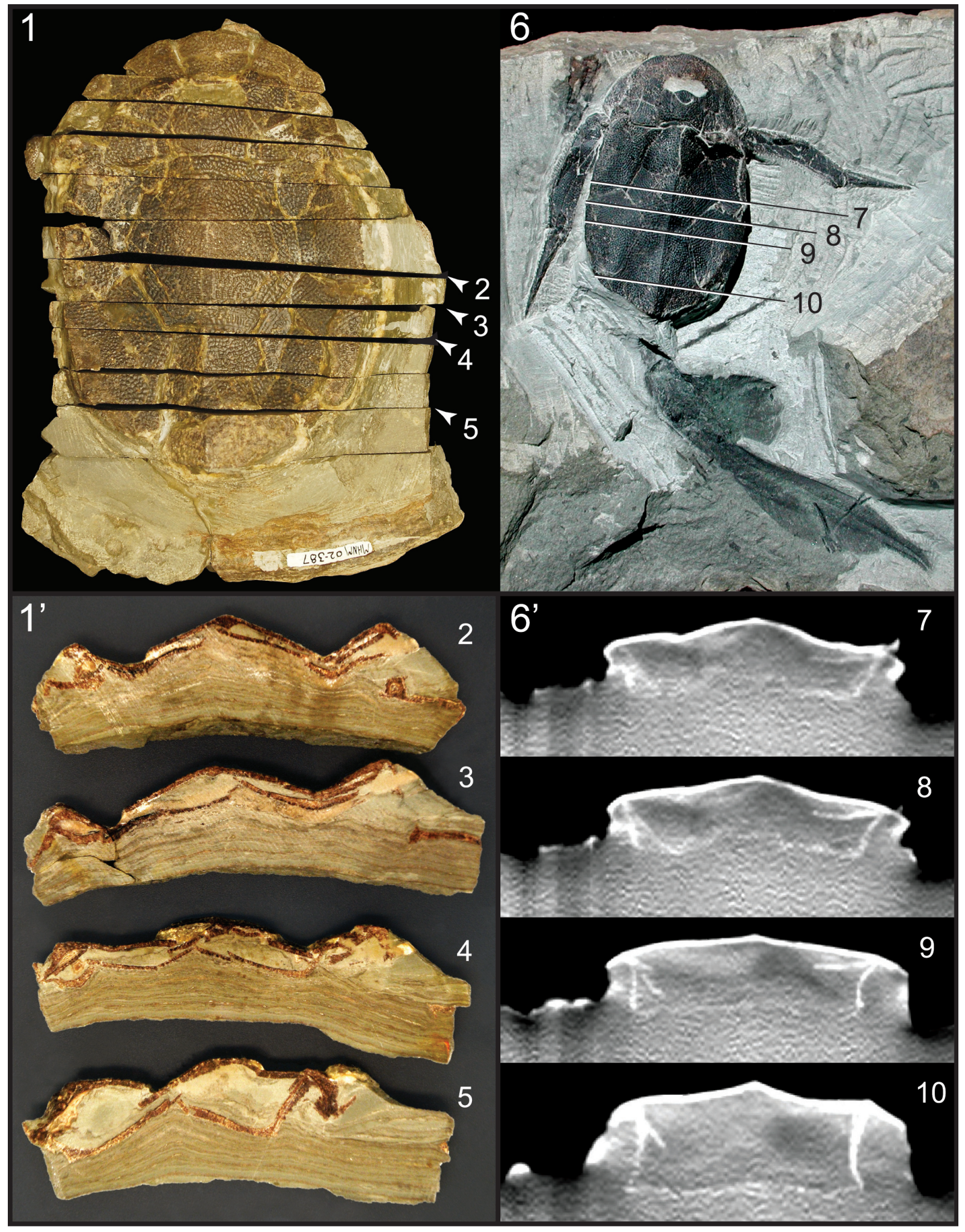

FIGURE 8. Taphonomic differences with reference to two types of sediment compaction for Bothriolepis canadensis: 1 and 1', specimen MHNM 02-387 in dorsal view preserved in laminites with coronal sectioned with positioning of the sections illustrated in 2-5; 2-5, coronal sections showing the flattening and distortion of the specimen; 6 and 6', specimen MHNM 02-2676 in dorsal view preserved in siltstone with positioning of the CT-scan coronal sections 7-10; 7-10, coronal sections showing the 3D condition of preservation and a weak lateral compaction. 
which is an underestimation. Associated with the collapsing of the thoracic armor, the cephalic armor is frequently flattened showing a ventral gap between the nuchal plate and the postmarginal plate, and gaps lateral to the premedian plate. All these taphonomic considerations have consequently altered previous reconstructions. The usage of $3 \mathrm{D}$ modeling software permits to rectify easily (without exhaustive quantitative procedures) taphonomic distortion.

Arsenault et al. (2004) used primarily two specimens (MHNM 02-2212 and 02-2116) buried perpendicularly to the stratigraphy to reconstruct the proportions of the armor. The position of fossilization minimized the taphonomic distortion owing to regular flattening. However, these two specimens differ in body size. In the present study, the smaller specimen (MHNM 02-2116) was used only to determine the inclination of the head, whereas the shape of the thoracic armor was obtained by combining the cast of specimen MHNM 02-2212 (for the posterior part of the thoracic armor) with a specimen of a similar size (MHNM 02-1561). As demonstrated by Werdelin and Long (1986), Bothriolepis canadensis displays allometric growth meaning that plate proportions differ between small (young) and large (older) individuals. Among other things, Stensiö (1948) and Werdelin and Long (1986) described the median dorsal ridge to be stronger in smaller individuals; however, this observation was made on specimens compressed dorso-ventrally. The edge of the median dorsal ridge is probably sharper in younger individual, giving the impression that the ridge is stronger developed, but it is actually higher than previously described for large adult specimens.

All previous reconstructions of Bothriolepis canadensis have been drawn as lateral, dorsal, ventral and anterior planar representations. We first noticed inaccuracies from these previous reconstructions when trying to combine different planar projections into a 3D model. In contrast to previous reconstructions, we built first a 3D model from which we visualized $2 \mathrm{D}$ projections.

\section{Functional Considerations}

Bothriolepis canadensis is frequently considered as a benthivorous, bottom-dweller fish (Watson, 1961; Moloshnikov, 2008; Cloutier et al., 2011). This paleobiological interpretation of $B$. canadensis comes primarily from an ecomorphological inference from the classical body shapei.e., flat trunk and head, dorsal position of the eyes, ventral position of the mouth. As we have demon- strated, the trunk is higher than expected, the head is higher and steeply inclined, eyes are rather in rostral position, but the mouth is still in ventral position. Is this new reconstruction of $B$. canadensis changing our paleobiological interpretation? With respect to the feeding content, $B$. canadensis fed at least in part on the conchostracan Asmusia membranacea (Cloutier et al., 2011; Cloutier, 2013) which most likely lived in the water column and near the bottom. Digestive tracks of $B$. canadensis most frequently include fine clastic sediment, which strongly suggests that it was foraging on or near the bottom; Arsenault et al. (2004) even suggested that it was limivorous. Thus, the new reconstruction of $B$. canadensis does not change the original palaeoecological interpretation. However, functional and behavioral interpretations are substantially challenged.

As suggested by Johanson (1997) for Bothriolepis yeungae, the forward movement of Bothriolepis canadensis would depend on propulsive forces generated by the lateral movement of the caudal fin. The relatively long trunk and caudal region of $B$. canadensis could have facilitated a subcarangiform locomotion although we are lacking information about the flexibility or rigidity of the axial skeleton since it remained cartilaginous throughout life. Comparison could also be made with an ostraciiform locomotion because of the boxedshape similarity of the anterior part of the body in antiarchs and boxfishes (tetraodontiform teleosts); however, Bothriolepis had a much longer part of flexible body than living boxfishes.

Most living fishes have, in addition to the caudal fin, a large dorsal fin and a pair of large pectoral fins to stabilize and steer. As numerous antiarchs, Bothriolepis canadensis had a well-developed heterocercal caudal fin, a fairly large dorsal fin, and narrow pectoral fins almost oar-shaped. The midtrunk position of a fairly robust dorsal fin in Bothriolepis canadensis most likely provided stability. It is unlikely that the dorsal fin had a significant role in propulsion as suggested by Johanson (1997). The dorsal fin most likely acted as a stabilizer (against rolling) in addition to the high-profiled shape of the posterior part of the median dorsal ridge of the thoracic armor. The shape (i.e., profile, trapezoidal cross-section, dorsal convexity, lateral concavity, presence of lateral keels and median dorsal ridge) of the thoracic armor of $B$. canadensis is comparable to the armor of living boxfishes (see Bartol et al., 2002, 2005). Similarly to boxfishes, a vortex sheet would have formed behind the trailing edge of the high profile of the posterior part of the 
median dorsal ridge. However, in contrast to boxfishes that lack dorsal fin, the vortex sheet was subsequently used by the dorsal and caudal fins. The shape of the thoracic armor and the height of the dorsal fin were important for stability since the anal fin is absent and the pectoral fins are narrow. During antiarch evolution (Young, 1988; Zhu, 1996; Zhu and Janvier, 1996; Johanson, 1998; Luksevics, 2001; Jia et al., 2010), modifications of the thoracic armor shape has been achieved independently and differently in order to increase the efficiency for stability. The median dorsal part of the thoracic armor has been transformed to project dorsally to form either a keel or a crest. In different taxa, the anterior and/or the posterior median dorsal plates are modified into: a high-profile, narrow median dorsal crest on both the anterior and posterior median dorsal plates [e.g., Bothriolepis gippslandiensis (Long, 1983; Young and Zhang, 1992), B. cullodenensis (Long, 1983), B. markovskii (Moloshnikov, 2010), B. fergusoni (Long, 1983), Grossaspis carinata (Denison, 1978)], a narrow dorsal crest on the anterior median dorsal plate [e.g., Sherbonaspis hillsi (Young and Zhang, 1992)], or a median spine on the anterior median dorsal plate [e.g., Byssacanthus dilatatus (Denison, 1978), Stegolepis jugata (Denison, 1978)]. Ningxialepis spinosa (Jia et al., 2010) possesses both a crest on the posterior median dorsal plate and a median dorsal spine located on the anterior and posterior median dorsal plates. Among these forms, the high-crested species are considered as a monophyletic group based on the presence of a pronounced median dorsal crest (Johanson, 1998, character 6). Although a significant size difference exists among the taxa which are not phylogenetically closely related (Zhu, 1996), the condition in $B$. canadensis is similar to that of Yunnanolepis porifera (Zhu, 1996) and Minicrania lirouyii (Zhu and Janvier, 1996) where the median dorsal ridge is highly profile posteriorly but not forming a narrow crest. Similar locomotory adaptations have been developed independently on the dorsal armor of pteraspidiform heterostracans (Botela and Farina, 2008).

Janvier (1996) mentioned that the function of the antiarch pectoral fins is still obscure. Various functions have been suggested with regard to the pectoral fins of antiarchs and more specifically Bothriolepis: (1) swimming maneuverability, (2) defense behavior, (3) anchoring device, and (4) terrestrial walking.

The fully retracted position allows the pectoral fins to lie on the lateral wall of the thoracic armor as noted by Young and Zhang (1992). Although we agree with Young and Zhang's (1992) interpretation, their statement concerning the greatest mobility in this position is incorrect. The fully retracted position of the pectoral fins allows only a limited rotational movement of $5^{\circ}$ around the brachial process (Figure 7.1). The fully protracted position allows the pectoral fins to open up to an angle of $70^{\circ}$ (Figure 7.2-3), in contrast with the almost right angle described by Young and Zhang (1992). In fully protracted position, rotational movements are not possible as previously noted by Young and Zhang (1992) because of the presence of the pars pedalis of the brachial process that fits in the lateral corner of the proximal brachial aperture. Thus, the stroke sequence described by Watson (1961) involving a rotational movement of the fins to bring them forward with the least water resistance is not supported by the present study. In fact, any hypothesis in which the pectoral fins would have been used for propelling in water (Stensiö, 1948) or crawling on land (Wells and Dorr, 1985) is not supported by the present study. Some authors (Stensiö, 1948; Young and Zhang, 1992; Johanson, 1997) proposed that the pectoral fins of Bothriolepis canadensis could have been used like a rudder for upward and downward navigation in the water. This hypothesis is possible if the pectoral fins are protracted in an angle around $16^{\circ}$. The range of movement $\left(32^{\circ}\right.$ around the brachial process and $15^{\circ}$ up-and-down) offered by this minimum protracted angle offers a great mobility for swimming maneuverability. Johanson (1998) considered that $B$. yeungae used its pectoral fins to generate lift to potentially feed within the water column; morphological similarity between $B$. yeungae and $B$. canadensis could suggest similar behavior.

Two types of defense behaviors associated with the usage of the pectoral fins have been suggested: (1) escaping behavior by burrowing in sediments (Janvier, 1996) and (2) anti-predatory display by adduction or swing-away movement of the fins (Johanson, 1998). Because of the slightly posterodorsal orientation of the fins, Janvier (1996) and Arseneault et al. (2004) suggested that the pectoral fins were used to throw fine sediments over its back, and thereby bury itself quickly. This behavior was compared to the ability of certain tropical crabs to bury themselves; similar behavior is also compatible with the sit-and-wait predatory behavior of stargazers (Uranoscopidae). With the overall movement of the pectoral fins and the latero-medial movement of the distal segment $\left(45^{\circ}\right)$, the hypothesis of burying by Janvier (1996) is inter- 
esting even if the mouth is ventral and the eyes are rostral rather than dorsal. However, if such a behavior would have been performed by Bothriolepis canadensis, one would expect an abundance of bioturbation resulting from such burrowing since $B$. canadensis is the most abundant vertebrate species from the Escuminac Formation. The entire stratigraphic sequence is almost completely devoid of bioturbation (Cloutier et al., 2011) and no ichnofossils are corresponding to such behavior (Maples, 1996).

Johanson $(1997,1998)$ suggested that the pectoral fins of both Bothriolepis yeungae and Remigolepis walkeri could be adducted or swung away to discourage predation through threat display. Although non homologous, pectoral spines of squeaker catfishes (Mochokidae, Siluriformes) are grossly similar to the pectoral fins of Bothriolepis, and they are used both to discourage predation because they have a locking system at the base, and to produce stridulation sounds during courtships and agonistic behaviour (Parmentier et al., 2010). A locking mechanism associated with the modified anteriormost lepidotrichium is found in various siluriforms (Arratia, 2003).

Wells and Dorr (1985) suggested that the pectoral fins of Bothriolepis could either serve as an anchoring devise to counteract strong currents or as an adaptation for walking on land over short distances. Both hypotheses are unlikely. The pectoral fins of $B$. canadensis could not be rotated ventrally to be used as anchoring devises. Finally, a walking locomotion over land is impossible from functional and anatomical standpoints. First, the pectoral fins of Bothriolepis have a limited mobility which prevents such locomotion. Second, the idea that $B$. canadensis could have survived outside water is based on the assumption that Bothriolepis had lungs (Denison, 1941). The presence of lungs in $B$. canadensis was not confirmed by the CT-scan performed for this study and is far from being corroborated in literature (Arsenault et al., 2004; Goujet, 2011).

\section{Conclusion}

The 3D model of Bothriolepis canadensis revealed unexpected anatomical novelties on a species that some would consider as one of the best known Devonian fish. The 3D model permitted correction on the fish silhouette for a more hydrodynamic one with a high dorsal median crest. The 3D model allowed us to investigate the articulation between the cephalic and thoracic armor in which a tight jointed head is supported by the present study. The gill opening is a novelty that was found by digital manipulation of the 3D material and could not be found in any other way. The 3D model also allows us to validate the ability of pectoral fin movements. The digital manipulation pointed out a fully retracted position along the lateral wall of the thoracic armor in contrast to a horizontally impossible position described in classic studies. Thus, fully retracted and protracted position of the pectoral fins permits only for restricted movement. For being used in swimming navigation, pectoral fins have to be protracted of a minimum angle to reach the maximum of mobility. Advantages to use digital models are numerous: (1) taphonomic distortion could be removed, (2) 2D projections are accurate to the 3D model, and (3) hypotheses of anatomical mobility could be tested by virtually moving elements.

\section{ACKNOWLEDGEMENTS}

We thank P. Bédard, director of the CDRIN, who provided technological material and supported the development of the mobile application PaleoAR. J.-M. Simard and J.-M. Philion, CEGEP de Matane, developed the mobile application PaleoAR and provided valuable technical assistance. O. Matton and J. Willet, Parc national de Miguasha, helped with the loan and preparation of the specimens, respectively. M. Bovo prepared specimen MHNM 02-3802. B. Long and L.-P. Daigle, from INRS-ETE, performed the CT-scan. Two anonymous referees provided constructive comments on the manuscript. This project was funded by a Chantier 3 grant (RC) from the Ministère de l'éducation, du loisir et du sport du Québec.

\section{REFERENCES}

Adams, T., Strganac, C., Polcyn, M.J., and Jacobs, L.L. 2010. High resolution three-dimensional laser-scanning of the type specimen of Eubrontes (?) glenrosensis Shuler, 1935, from the Comanchean (Lower Cretaceous) of Texas: implications for digital archiving and preservation. Palaeontologia Electronica, 13(3):11. http://palaeo-electronica.org/2010_3/ 226/index.html

Araújo, R. and Polcyn, M.J. 2013. A biomechanical analysis of the skull and adductor chamber muscles in the Late Cretaceous Plesiosaur Libonectes. Palaeontologia Electronica,16(2):25. http://palaeo-electronica.org/content/2013/418-plesiosaur-mastication

Arratia, G. 2003. The siluriform postcranial skeleton. An overview, p. 121-157. In Arratia, G., Kapoor, B. G., Chardon, M., and Diogo, R. (eds.), Catfishes. Science Publishers, Inc., Enfield. 
Arsenault, M., Desbiens, S., Janvier, P., and Kerr, J. 2004. New data on the soft tissues and external morphology of the antiarch Bothriolepis canadensis (Whiteaves, 1880), from the Upper Devonian of Miguasha, Québec, p. 439-454. In Arratia, G., Wilson, M.V.H., and Cloutier, R. (eds.), Recent Advances in the Origin and Early Radiation of Vertebrates. Verlag Dr. Friedrich Pfeil, Munich.

Bartol, I.K., Gharib, M., Webb, P.W., Weihs, D., and Gordon, M.S. 2005. Body-induced vortical flows: a common mechanism for self-corrective trimming control in boxfishes. Journal of Experimental Biology, 208:327-344. http://jeb.biologists.org/content/208/2/ 327.full

Bartol, I.K., Gordon, M.S., Gharib, M., Hove, J.R., Webb, P.W., and Weihs, D. 2002. Flow patterns around the carapaces of rigid-bodied, multi-propulsor boxfishes (Teleostei: Ostraciidae). Integrative and Comparative Biology, 42:971-980.

Bates, K.T., Manning, P.L., Vila, B., and Hodgetts, D. 2008. Three-dimensional modelling and analysis of dinosaur trackways. Palaeontology, 51:999-1010.

Bennett, M.R., Falkingham, P., Morse, S.A., Bates, K., and Crompton, R.H. 2013. Preserving the impossible: Conservation of soft-sediment hominin footprint sites and strategies for three-dimensional digital data capture. PLoS One, 8(4):15. http://www.plosone.org/ article/info\%3Adoi\%2F10.1371\%2Fjournal.pone.0060755

Botella, H. and Farina, R.A. 2008. Flow pattern around the rigid cephalic shield of the Devonian agnathan Errivaspis waynensis (Pteraspidiformes: Heterostraci). Palaeontology, 51:1141-1150.

Cloutier, R. 2013. Great Canadian Lagerstätten 4. The Devonian Miguasha biota (Quebec): an UNESCO World Heritage, a time capsule in the early history of vertebrates. Geoscience Canada 40:149-163. http:// journals.hil.unb.ca/index.php/gc/article/view/geocanj.2013.40.008/24239

Cloutier, R., Béchard, I., Charest, F., and Matton, O. 2009. La contribution des poissons fossiles du parc national de Miguasha à la biologie évolutive du développement. Le Naturaliste canadien, 133(3):84-95. http://www.provancher.qc.ca/upload/file/NatCan\%20133_3\%20p\%2084-95.pdf

Cloutier, R., Loboziak, S., Candilier, A.-M., and Blieck, A. 1996. Biostratigraphy of the Upper Devonian Escuminac Formation, eastern Quebec, Canada: A comparative study based on miospores and fishes. Review of Palaeobotany and Palynology, 93:191-215.

Cloutier, R., Proust, J.-N., and Tessier, B. 2011. The Miguasha Fossil-Fish-Lagerstätte: A consequence of the Devonian land-sea interactions. Palaeobiodiversity and Palaeoenvironments, 91:293-323.

Denison, R.H. 1978. Placodermi. In Schultze, H.-P., (ed.), Handbook of Paleoichthyology, 2. Gustav Fischer Verlag, Stuttgart.
Falkingham, P.L. 2012. Acquisition of high resolution three-dimensional models using free, open-source, photogrammetric software. Palaeontologia Electronica, 15(1):15. http://palaeo-electronica.org/content/ issue1-2012technical-articles/92-3d-photogrammetry

Goujet, D. 2011. "Lungs" in placoderms, a persistent palaeobiological myth related to environmental preconceived interpretations. Comptes Rendus Palevol, 10:323-329.

Gunz, P., Mitteroecker, P., Neubauer, S., Weber, G.W., and Bookstein, F.L. 2009. Principles for the virtual reconstruction of hominin crania. Journal of Human Evolution, 57(1):48-62.

Janvier, P. 1996. Early Vertebrates. Oxford University Press, Oxford, New York.

Jia, L.-T., Zhu, M., and Zhao, W.-J. 2010. A new antiarch fish from the Upper Devonian Zhongning Formation of Ningxia China. Palaeoworld 19:136-145.

Johanson, Z. 1997. New Remigolepis (Placodermi; Antiarchi) from Canowindra, New South Wales, Australia. Geological Magazine, 134:813-846.

Johanson, Z. 1998. The Upper Devonian fish Bothriolepis (Placodermi: Antiarchi) from near Canowindra, New South Wales, Australia. Records of the Australian Museum, 50:315-348.

Johanson, Z. 2002. Vascularization of the osteostracan and antiarch (Placodermi) pectoral fin: similarities, and implications for placoderm relationships. Lethaia, 35:169-186.

Long, J.A. 1983. New bothriolepid fish from the Late Devonian of Victoria, Australia. Palaeontology, 26:295-320.

Lukševičs, E. 2001. Bothriolepid antiarchs (Vertebrata, Placodermi) from the Devonian of the north-western part of the East European Platform. Geodiversitas 23:489-609.

Lyons, P.D., Rioux, M., and Patterson, R. T. 2000. Application of a three-dimensional color laser scanner to paleontology: An interactive model of a juvenile Tylosaurus sp. basisphenoid-basioccipital. Palaeontologia Electronica, 3(2):16. http://palaeo-electronica.org/ 2000_2/neural/issue2_00.htm

Maples, C.G. 1996. Paleoenvironmental significance of trace fossils in the Escuminac Formation, p. 114-119. In Schultze, H.-P. and Cloutier, R. (eds.), Devonian Fishes and Plants of Miguasha, Québec, Canada. Verlag Dr. Friedrich Pfeil, München.

McAllister, J. 1996. Coprolitic remains from the Devonian Escuminac Formation, p. 328-347. In Schultze, H.-P. and Cloutier, R. (eds.), Devonian Fishes and Plants of Miguasha, Quebec, Canada. Verlag Dr. Friedrich Pfeil, München.

Molnar, J.L., Pierce, S.E., Clack, J.A., and Hutchinson, J.R. 2012. Idealized landmark-based geometric reconstructions of poorly preserved fossil material: a case study of an early tetrapod vertebra. Palaeontologia Electronica, 15(1):18. http://palaeo-electronica.org/content/issue-1-2012-technical-articles/165digital-fossil-restoration 
Moloshnikov, S. 2008. The placoderm Plourdosteus livonicus (Eastman) in the early Frasnian of the Central Devonian Field and the trophic structure of the Mikhailovskii Fish Assemblage. Paleontological Journal, 42:607-614.

Moloshnikov, S.V. 2008. Devonian antiarchs (Pisces, Antiarchi) from central and Southern European Russia. Paleontological Journal, 42:691-773.

Moloshnikov, S.V. 2010. On high-armor bothriolepidid placoderms (Pisces, Placodermi, Bothriolepididae) from the Upper Devonian of the southern Ural Mountains and Kuznetsk Coal Basin. Paleontological Journal, 44:561-566.

Myers, G.S. 1942. The "lungs" of Bothriolepis. Stanford Ichthyological Bulletin, 2:134-136.

Neamtu, C., Popescu, S., Popescu, D., and Mateescu, R. 2012. Using reverse engineering in archaeology: Ceramic pottery reconstruction. Journal of Automation, Mobile Robotics and Intelligent Systems 6(2):55-59.

Parent, N. and Cloutier, R. 1996. Distribution and preservation of fossils in the Escuminac Formation, p. 5478. In Schultze, H.-P. and Cloutier, R. (eds.), Devonian Fishes and Plants of Miguasha, Quebec, Canada. Verlag Dr. Friedrich Pfeil, München.

Parmentier, E., Fabri, G., Kaatz, I., Decloux, N., Planes, S., and Vandewalle, P. 2010. Functional study of the pectoral spine stridulation mechanism in different mochokid catfishes. Journal of Experimental Biology, 213:1107-1114.

Patten, W. 1904. New facts concerning Bothriolepis. Biological Bulletin, 7:113-124.

Patten, W. 1912. The Evolution of the Vertebrates and their Kin. P. Blakiston's son \& Co., Philadelphia.

Remondino, F., Rizzi, A., Girardi, S., Petti, F.M., and Avanzini, M. 2010. 3D Ichnology-recovering digital 3D models of dinosaur footprints. Photogrammetric Record, 25(131):266-282.

Stensiö, E.A. 1948. On the Placodermi of the Upper Devonian of East Greeenland. II. Antiarchi: subfamily Bothriolepinae. With an attempt at a revision of the previously described species of that family. Meddelelser om Grønland, 139:1-622.

Thomson, K.S. and Thomas, B. 2001. On the status of species of Bothriolepis (Placodermi, Antiarchi) in North America. Journal of Vertebrate Paleontology, 21:679-686.
Vézina, D. 1996. Placodermi (Antiarchi and Arthrodira), p. 141-148. In Schultze, H.-P. and Cloutier, R. (eds.), Devonian Fishes and Plants of Miguasha, Quebec, Canada. Verlag Dr. Friedrich Pfeil, München

Watson, D.M.S. 1961. Some additions to our knowledge of antiarchs. Palaeontology, 4:210-220.

Wells, N.A. and Dorr, J.A. 1985. Form and function of the fish Bothriolepis (Devonian: Placodermi, Antiarchi): The first terrestrial vertebrate? Michigan Academician, 17:157-173.

Werdelin, L. and Long, J.A. 1986. Allometry in the placoderm Bothriolepis canadensis and its significance to antiarch evolution. Lethaia, 19:161-169.

Whiteaves, J.F. 1880. On a new species of Pterichthys, allied to Bothriolepis ornata, from the Devonian rocks of the north side of the Baie des Chaleurs. American Journal of Science, 3:132-136.

Young, G.C. 1984. Reconstruction of the jaws and braincase in the Devonian placoderm fish Bothriolepis. Palaeontology, 27:625-661.

Young, G.C. 2008. The relationships of antiarchs (Devonian placoderm fishes) - Evidence supporting placoderm monophyly. Journal of Vertebrate Paleontology, 28:626-636.

Young, G.C. 2010. Placoderms (armored fish): Dominant vertebrates of the Devonian period, p. 523-550. In Jeanloz, R. and Freeman, K.H. (eds.), Annual Review of Earth and Planetary Sciences, Vol. 38. Annual Review of Earth and Planetary Sciences. Annual Reviews, Palo Alto.

Young, G.C. and Zhang, G.R. 1992. Structure and function of the pectoral joint and operculum in antiarchs, Devonian placoderm fishes. Palaeontology, 35:443464.

Zhu, M. 1996. The phylogeny of the Antiarcha (Placodermi, Pisces), with the description of Early Devonian antiarchs from Qujing, Yunnan, China. Bulletin $d u$ Muséum national d'Histoire naturelle, Section C 18(2-3):233-347.

Zhu, M. and Janvier, P. 1996. A small antiarch, Minicrania lirouyii gen. et sp. nov., from the Early Devonian of Qujing, Yunnan (China), with remarks on antiarch phylogeny. Journal of Vertebrate Paleontology, 16:115. 